\title{
Validation of Portuguese version of Quality of Erection Questionnaire (QEQ) and comparison to International Index of Erectile Function (IIEF) and RAND 36-Item Health Survey
}

\author{
Ana Luiza Reis ${ }^{1}$, Leonardo Oliveira Reis ${ }^{1,2}$, Ricardo Destro Saade ${ }^{1}$, Carlos Alberto Santos Jr. ${ }^{1}$, Marcelo \\ Lopes de Lima ${ }^{1}$, Adriano Fregonesi ${ }^{1}$ \\ ${ }^{1}$ Department of Surgery (Urology), Faculty of Medical Sciences, University of Campinas (Unicamp), \\ Brazil; ${ }^{2}$ Medicine (Urology), Center for Life Sciences, Pontifical Catholic University of Campinas (PUC- \\ Campinas), Brazil
}

\begin{abstract}
Purpose: To validate the Quality of Erection Questionnaire (QEQ) considering Brazilian social-cultural aspects.

Materials and Methods: To determine equivalence between the Portuguese and the English QEQ versions, the Portuguese version was back-translated by two professors who are native English speakers. After language equivalence had been determined, urologists considered the QEQ Portuguese version suitable. Men with self-reported erectile dysfunction (ED) and infertile men who had a stable sexual relationship for at least 6 months were invited to answer the QEQ, the International Index of Erectile Function (IIEF) and the RAND 36-Item Health Survey (RAND-36). The questionnaires were presented together and answered without help in a private room. Internal consistency (Cronbach's $\alpha$ ), test-retest reliability (Spearman), convergent validity (Spearman correlation) coefficients and known-groups validity (the ability of the QEQ Portuguese version to differentiate erectile dysfunction severity groups) were assessed.

Results: We recruited 197 men (167 ED patients and 30 non-ED patients), mean age of 53.3 and median of 55.5 years (23-82 years). The Portuguese version of the QEQ had high internal consistency (Cronbach $\alpha=0.93$ ), high stability between test and retest (ICC 0.83, with IC 95\%: 0.76-0.88, $\mathrm{p}<0.001$ ) and Spearman correlation coefficient $\mathrm{r}=0.82$ $(\mathrm{p}<0.001)$, which demonstrated the high correlation between the QEQ and IIEF results. The correlations between the QEQ and RAND-36 were significantly low in ED ( $r=0.20$, $\mathrm{p}=0.01$ ) and non-ED patients $(\mathrm{r}=0.37, \mathrm{p}=0.04)$.

Conclusion: The QEQ Portuguese version presented good psychometric properties and high convergent validity in relation to IIEF. The low correlations between the QEQ and the RAND-36, as well as between the IIEF and the RAND-36 indicated IIEF and QEQ specificity, which may have resulted from the patients' psychological adaptations that minimized the impact of ED on Quality of Life (QoL) and reestablished the well-being feeling.
\end{abstract}

\section{ARTICLE INFO}

\section{Key words:}

Erectile Dysfunction; Quality of Erection Questionnaire; Quality of Life; Cross-cultural adaptation

Int Braz J Urol. 2015; 41: 155-67

Submitted for publication:

December 02, 2013

Accepted after revision:

September 16, 2014

\section{INTRODUCTION}

Erectile dysfunction (ED) is defined as the inability to obtain or maintain an erection long enough to achieve a satisfactory sexual activity. ED affects from 12 to $69 \%$ males in the world, depending on the age group (1-7). The number of affected Brazilian men ranges from 3 to 48\%, 
depending on the measurement instrument used, being more prevalent in individuals of low educational level, and those who are hypertensive or diabetic $(8,9)$.

Clinical studies commonly use questionnaires in the evaluation of ED due to their capacity to evaluate physical, psychological and social aspects $(10,11)$. The International Index of Erectile Function (IIEF), and its short version IIEF-5, is one of the most used instruments. The IIEF is considered the gold standard and the IIEF- 5 is largely used because of its short length with only 5 questions. However, the coverage of the multiple aspects of male sexuality besides erection by both instruments is questioned (12), since they deal only superficially with the patients' perception and satisfaction with their erections (13).

With the appearance of various ED treatment options, the assessment of self-perceived penile hardness has received more attention and been the subject of studies that have led to the development of a new short and patient-friendly assessment instrument, the "Quality of Erections Questionnaire” (QEQ) (13). It measures the patients' satisfaction with their erections and identifies those who would like to undergo treatment (14).

Since the QEQ covers physical, psychological and social aspects of male sexuality and focuses more on penile hardness and the patients' individual needs, it provides a differential assessment in relation to the IIEF $(14,15)$. This may favor the follow-up of clinical and psychosocial response to non-pharmacological ED treatment, such as physical therapy, and changes in life style. Apart from focusing on the erectile function, it is important to determine the impact of ED on quality of life (QoL). This study describes the correlations between the QEQ and the IIEF results in the quantification of ED and the QoL measured with the RAND-36, an instrument similar to the SF-36 (16), but which has a simpler scoring system and is publicly available.

\section{MATERIALS AND METHODS}

\section{QEQ Translation and validation}

The original English version of the QEQ was made publicly available by Pfizer New York $^{\circledR}$ and has been translated to Brazilian Portuguese. After obtaining the author's permission, the QEQ was translated and backtranslated by two professors fluent in English for analysis of equivalence between the versions in the two languages. Next, urologists evaluated the adequacy of the Portuguese version (Figure-1).

\section{Subjects}

After approval of this study by Unicamp's ethics committee, 197 patients from a public andrology clinic were consecutively invited during routine consultations to participate in this study from January 2009 to February 2012 (Figure-2). The patient inclusion criteria were: having had a stable sexual partner for at least six months, being literate and over 18 years of age. The exclusion criteria were refusal to participate in the study and the use of IPDE- 5 between the test and retest. If the patients were already using oral or injectable ED medication, they were instructed to answer the questions considering the effect of the medication in use.

The patients were informed about the purpose of the study by the examiner privately. After giving their written informed consent, the patients were requested to fill in an evaluation sheet and answer the QEQ and RAND-36. The evaluation sheet items were age, skin color, marital status, occupation, level of education, monthly income.

Concerning diseases, the patients were asked about their ability to walk with or without aid, neurological diseases, diabetes, hypertension, heart disease, androgen deficiency of the aging male (ADAM), urological examination for description of the anatomic part and type of treatment received, when ED symptoms started and whether the treatment had already been started. The patients also replied questions concerning their life style such as alcoholism, smoking, regular physical exercising and number of attempts of sexual intercourse in the previous month.

The answers were checked after the patients had answered the evaluation sheets and the patients were asked to complete any missing information. When the questionnaires were fully answered, a new date was scheduled for the QEQ retest at about 28 days after the first test. 


\section{Figure 1 - Final version of the EQF in Portuguese}

\section{Questionário de Qualidade da Ereção (QEQ)}

As questões seguintes perguntam sobre a qualidade das suas ereções ao longo das últimas quatro semanas. Por favor, para cada questão assinale a opção que melhor descreve sua resposta.

Ao responder estas questões, observe as seguintes definiç̧ões:

Atividade sexual inclui relação sexual, carícias, brincadeiras amorosas e masturbação.

Relação sexual é definida como penetração (entrada) na vagina da parceira.

Satisfatória é definida como atingir suas expectativas, ter sucesso na relação sexual.* Insatisfatória é definida como falha das suas expectativas, falha do sucesso na relação sexual.*

1. Você teve ereções suficientemente duras para permitir a penetração em sua parceira

Quase sempre ou sempre

Mais da metade do tempo

Cerca da metade do tempo

Menos da metade do tempo

Quase nunca ou nunca

2. Sua habilidade para manter sua ereção até o final da relação sexual foi:

Muito satisfatória

Um pouco satisfatória

Nem satisfatória nem insatisfatória

Um pouco insatisfatória

Muito insatisfatória

3. A quantidade de tempo (desde que começou a atividade sexual) até que a sua ereção fosse suficientemente dura para participar de uma relação sexual foi:

Muito satisfatória

Um pouco satisfatória

Nem satisfatória nem insatisfatória

Um pouco insatisfatória

Muito insatisfatória 
Figure 2 - Study flow chart.






\section{Instruments}

To compare the instruments of measurement of sexual life and QoL, we took into account the time aspect. The questions of all the instruments used in this study (QEQ, IIEF and RAND-36) concerned the month previous to the survey.

\section{IIEF}

The IIEF was originally developed in English and validated for the assessment of the degree of severity of erectile dysfunction. It is made up of 15 items. It was translated to Portuguese (17) and validated in Brazil in 2013 (18) and is also available in another 32 languages (19). The questionnaire comprises five domains: erectile function, orgasm, sexual desire, sexual satisfaction and general satisfaction. The IIEF score is compartmentalized and ranges from 1 to 75 points.

The erectile function domain classifies the patients into five categories depending on the degree of severity of ED. Between 26 and 30 points, the individual is considered normal or without erectile dysfunction, between 22 and 25 point, as having mild ED, between 17 and 21 points, as having mild/moderate ED, between 11 and 16, with moderate ED, and from 1 to 10 points, with severe ED.

The sensitivity and specificity are adequate but the IIEF is limited by the exclusion of other aspects of male sexuality and the relationship with a partner (19).

\section{QEQ}

The QEQ was developed and validated in English and is made up of six items. It focuses on the patients' satisfaction with the quality of their erections. It takes into account the quality of erection, time necessary to achieve an erection and its duration (13-15).

The instrument can be filled out in $3 \mathrm{~min}$ and is sensitive in the assessment of changes resulting from effective ED treatments. It has demonstrated high internal consistency and one-dimensional structure. The final score ranges from 0 to 100 points. The higher the score, the better the quality of erection (13-15).

\section{RAND 36-Item Health Survey}

The RAND-36 is a general QoL evaluation instrument. It assesses physical aspects, pain, functional capacity, mental health, emotional aspects, social aspects, vitality and general health condition. Its questions are similar to those of the MOS SF-36 $(16,20)$, but it has a simplified score, developed by the International Resource Center for Health Care. All 36 items are scored from 10 to $100 \%$, the higher the score, the better the health condition.

\section{Statistical analysis}

The study sample was profiled according to the investigation variables using frequency tables of categorical variables with absolute frequency (n) and percentage (\%) values and descriptive statistics for continuous variables. Categorical variables were compared between groups using the Fisher exact test. Numerical variables were evaluated between two groups using the Mann-Whitney test, and between three or more groups with the Kruskal-Wallis test due to the lack of normal distribution of the variables.

The Spearman correlation coefficient was used to analyze the correlation between numerical variables. The QEQ (Brazil) score temporal stability (test-retest) was assessed with intra-class correlation (ICC), and the internal consistency of the translated version, with Cronbach's alpha coefficient. The statistical significance level for the tests was $5 \%(\mathrm{p}<0.05)$.

\section{RESULTS}

Of the 197 respondents, most were white, 167 self-reported ED, were aged between 23 and 82 years, with a mean age of 57 and median of 58.5 years. The time elapsed before ED complaint varied from 0.3 to 25 years, with a mean of 4.9 years. 30 of the men without ED were under medical follow-up for infertility, age range of 23-61, mean age of 34 and median of 33 years.

Two of the men with self-reported ED declined to participate in the study and three were excluded because they used IPDE- 5 between the test and the retest. Patients with infertility complaint 
Table 1 - Caracteristics of patients with erectile dysfunction.

\begin{tabular}{|c|c|c|c|}
\hline Variable & $\begin{array}{c}\text { QEQ } \\
\text { Test }- \text { Retest }(n=101)\end{array}$ & $\begin{array}{c}\text { QEQ } \\
\text { No Retest }(\mathrm{n}=61)\end{array}$ & $p$ \\
\hline Age (mean) & $58(23-82)$ & $55.08(23-78)$ & 0.260 \\
\hline Sexual frequency (per month) & $6.37(0-28)$ & $4.88(0-28)$ & 0.340 \\
\hline Time from the beginning of symptoms (Years) & $4.72(0.3-20)$ & $5.13(0.3-25)$ & 0.480 \\
\hline Use of PDE-5 inhibitor & $33(32.67 \%)$ & $22(36.07 \%)$ & 0.660 \\
\hline \multicolumn{4}{|l|}{ Race } \\
\hline White & $90(89.11 \%)$ & $43(70.5 \%)$ & \multirow{3}{*}{0.007} \\
\hline Black & $4(3.96 \%)$ & $10(16.39 \%)$ & \\
\hline "Brown" (Black/White) & $7(6.93 \%)$ & $8(13.11 \%)$ & \\
\hline \multicolumn{4}{|l|}{ Age (decades) } \\
\hline$<50$ years & $24(23.76 \%)$ & $18(29.51 \%)$ & \multirow{4}{*}{0.850} \\
\hline $50-59$ years & $29(28.71 \%)$ & $16(26.23 \%)$ & \\
\hline $60-69$ years & $32(31.68 \%)$ & $19(31.15 \%)$ & \\
\hline$\geq 70$ years & $16(15.84 \%)$ & $8(13.11 \%)$ & \\
\hline \multicolumn{4}{|l|}{ Familiar income per month* } \\
\hline$\leq 300$ & $19(18.81 \%)$ & $20(32.79 \%)$ & \multirow{4}{*}{0.094} \\
\hline 600 & $33(32.67 \%)$ & $21(34.43 \%)$ & \\
\hline 900 & $44(43.56 \%)$ & $16(26.23 \%)$ & \\
\hline$\geq 1200$ & $5(4.95 \%)$ & $4(6.56 \%)$ & \\
\hline \multicolumn{4}{|l|}{ Literacy } \\
\hline Literate & $70(69.30 \%)$ & $51(83.61 \%)$ & \multirow{3}{*}{0.130} \\
\hline High school & $25(24.75 \%)$ & $6(9.84 \%)$ & \\
\hline More than high school & $6(5.94 \%)$ & $4(6.56 \%)$ & \\
\hline \multicolumn{4}{|l|}{ Co-morbidities } \\
\hline Diabetes & $36(35.64 \%)$ & $16(26.23 \%)$ & 0.210 \\
\hline Hypertension & $54(53.47 \%)$ & $29(47.54 \%)$ & 0.460 \\
\hline Hypercolesterolemia & $18(17.82 \%)$ & $20(32.79 \%)$ & 0.020 \\
\hline Hormonal treatment & $10(9.9 \%)$ & $1(1.64 \%)$ & 0.054 \\
\hline Radiotherapy & $6(5.94 \%)$ & $4(6.56 \%)$ & 1 \\
\hline Radical prostatectomy & $6(5.94 \%)$ & $5(8.2 \%)$ & 0.710 \\
\hline Alcoholism & $23(22.77 \%)$ & $15(24,6 \%)$ & 0.790 \\
\hline Smoking & $10(9.9 \%)$ & $12(19,67 \%)$ & 0.080 \\
\hline Sedentarism & $56(55 \%)$ & $30(49 \%)$ & 0.430 \\
\hline
\end{tabular}

PDE-5 = phosphodiesterase type 5 / ** in American dollars (calculated by the authors using currency date 29/11/2012) 
Table 2 - Caracteristics of patients without erectile dysfunction.

\begin{tabular}{|c|c|}
\hline Variables & $n=30$ \\
\hline Age (mean) & $34(23-61)$ \\
\hline Sexual frequency (per month) & $11(2-28)$ \\
\hline \multicolumn{2}{|l|}{ Race } \\
\hline White & $29(97 \%)$ \\
\hline Black & $1(3 \%)$ \\
\hline "Brown” (Black/White) & 0 \\
\hline \multicolumn{2}{|l|}{ Familiar income per month* } \\
\hline$\leq 300$ & $1(3 \%)$ \\
\hline 600 & $10(33 \%)$ \\
\hline 900 & $12(40 \%)$ \\
\hline$\geq 1200$ & $7(23.33 \%)$ \\
\hline \multicolumn{2}{|l|}{ Literacy } \\
\hline Literate & $4(13 \%)$ \\
\hline High school & $18(60 \%)$ \\
\hline More than high school & $8(27 \%)$ \\
\hline \multicolumn{2}{|l|}{ Co-morbidities } \\
\hline Diabetes & $2(7 \%)$ \\
\hline Hypertension & $2(7 \%)$ \\
\hline Hypercolesterolemia & 0 \\
\hline Hormonal treatment & 0 \\
\hline Radiotherapy & 0 \\
\hline Radical prostatectomia & 0 \\
\hline Etilism & $1(3 \%)$ \\
\hline Smoking & $2(7 \%)$ \\
\hline Sedentarism & $19(63 \%)$ \\
\hline
\end{tabular}

*In American dollars (calculated by the authors using currency date 29/11/2012)

and without ED were intentionally included in this study for evaluation of equivalence of the questionnaires in the absence of ED. Age distribution and social and ethnic characteristics are detailed in Tables 1 and 2. The scores of men with self-reported ED are given in Table-3.

Some of the patients with ED $(n=61)$ did not participate in the retest. However, the group of ED patients who did not come for or interrupted the retest was considered statistically homogeneous and were considered as a single group, the only significant difference being a greater number of hypercholesterolemia (Table-1).
The Portuguese version of the QEQ had high internal consistency ( $\alpha$ Cronbach 0.93), high stability between test and retest (ICC 0.83 , with IC 95\%: 0.76, 0.88, p<0.001) and a Spearman correlation coefficient $\mathrm{r}=0.82(\mathrm{p}<0.001)$, which confirmed the high correlation between the values. No floor or ceiling effects were observed for ED patients that might compromise the reliability of the questionnaire translated into Portuguese, QEQ 0\% in 15.43\% and QEQ $100 \%$ in $4.32 \%$.

The IIEF and QEQ scores of the population as a whole, including both ED and non-ED patients, were correlated. The strongest correlations were found between QEQ and total IIEF $(\mathrm{r}=0.73, \mathrm{p}<0.001)$, between QEQ and Erectile Function $(\mathrm{r}=0.71, \mathrm{p}<0.001)$ and between QEQ and the general sexual satisfaction domain $(\mathrm{r}=0.73, \mathrm{p}<0.001)$. The correlation values are given in Table-4.

When the sample was stratified according to ED severity, as measured by the IIEF erectile function domain, significant differences were also observed between QEQ scores of non-ED and mild-to-severe ED men. The mean QEQ score difference for ED severity was 16.8 points. All values are given in Table- 5 .

The correlation between the QEQ and RAND-36 scores was $r=0.40, p<0.0001$; the domain details are given in Table 4 . The comparison of the scores of the respondents within the same ED severity range according to the IIEF erectile function domain score revealed a difference between non-ED (mean total RAND36 score $85.96 \%$ ) and ED patients (mean total RAND-36 score $64.86 \%$ ) for $\mathrm{p}<0.001$ (Table-6). Additionally, there were differences between the RAND-36 general health perception of mild ED and moderate ED patients and between the scores of mild Ed and severe ED patients for $p<0.0001$. No statistical difference was found between the other ED patient groups (mild to severe).

Regarding the age of the respondents, the QEQ score was inversely proportional to age $(r=-0.32 p<0.0001)$. The reported frequency of sexual intercourse correlated with the QEQ scores $(\mathrm{r}=0.45, \mathrm{p}<0.0001)$. 
Table 3 - Scores of IIEF, QEQ and RAND 36-Itens for patients with erection dysfunction.

\begin{tabular}{lccccc}
\hline SCORES & N & Mean & Median & Min-Max. & SD \\
\hline $\begin{array}{l}\text { International Index of Erectile Function } \\
\text { Total }\end{array}$ & 162 & 34.99 & 33.5 & $5-75$ & 17.33 \\
Subdomains & & & & & \\
$\quad$ Erectile function & 162 & 13.12 & 12 & $1-48$ & 8.51 \\
$\quad$ Orgasmic function & 162 & 5.38 & 5 & $0-10$ & 3.57 \\
$\quad$ Sexual desire & 162 & 6.36 & 6.5 & $0-10$ & 2.48 \\
$\quad$ Intercourse satisfaction & 162 & 5.65 & 5.5 & $0-15$ & 4.19 \\
$\quad$ Overall satisfaction & 162 & 4.68 & 4 & $0-10$ & 2.69 \\
Quality of Erections Questionnaire & & & & & \\
$\quad$ Test & 162 & $41.74 \%$ & $37.50 \%$ & $0-100 \%$ & 31.89 \\
$\quad$ Retest & 101 & $38.66 \%$ & $41.66 \%$ & $0-100 \%$ & 33.04 \\
RAND 36-Item Health Survey & & & & & \\
Total & $\mathbf{1 6 2}$ & $\mathbf{6 4 . 3 6} \%$ & $\mathbf{6 7 . 7 8 \%}$ & $\mathbf{8 . 7 5 - 9 5 \%}$ & $\mathbf{2 0 . 7 4}$ \\
$\quad$ Physical functioning & 162 & $69.79 \%$ & $80 \%$ & $0-100 \%$ & 28.67 \\
$\quad$ Role limitations due physical problems & 162 & $57.41 \%$ & $50 \%$ & $0-100 \%$ & 39.79 \\
$\quad$ Role limitations due emotional problems & 162 & $60.90 \%$ & $66.67 \%$ & $0-100 \%$ & 40.63 \\
$\quad$ Vitality & 162 & $61.55 \%$ & $65 \%$ & $0-100 \%$ & 23.69 \\
$\quad$ General mental health & 162 & $65.39 \%$ & $68 \%$ & $0-100 \%$ & 24.5 \\
$\quad$ Social Functioning & 162 & $70.68 \%$ & $75 \%$ & $0-100 \%$ & 28.46 \\
$\quad$ Bodily pain & 162 & $64.46 \%$ & $67.50 \%$ & $0-100 \%$ & 27.84 \\
$\quad$ General health perceptions & 162 & $57.16 \%$ & $61.25 \%$ & $12.5-100 \%$ & 21.56 \\
\hline
\end{tabular}

\section{DISCUSSION}

The use of questionnaires in ED research and evaluation is supported by arguments such as better ED symptom evaluation and treatment response $(9,17)$, greater rate of detection when compared to isolated questions (19) and improvement of communication between health professionals and patients about a subject still surrounded by "taboos", like impotency (21).

However, their supporters and critics are as many as the varied options of questionnaires. In clinical studies, the IIEF remains the gold standard $(10,11)$ despite its limitations: length and non-specificity to sexual performance, since it does not distinguish ED from premature ejaculation or alterations in sexual desire (11). The IIEF-5 complies with the health consensus guidelines regarding the evaluation of sexual performance in the previous 6 months (22). However, studies indicate a high ceiling effect, that is, a maximal score in $50 \%$ of the sample that impairs clinical assessment $(12,23)$. They also point out is use being limited to clinical practice because of the time period it covers (11).

The study sample was similar to those of other epidemiological studies, with a mean age of 53.3 years and association of ED with chronic diseases $(1,6,24)$. In agreement with Araújo et al., 2004 (25), we also observed poorer erection with aging. Regarding ethnicity, white race predominated $(p=0.007)$, which agrees with the general population of Southeast Brazil (26), where most of the population self-reported to be white or of European ancestry. 
Table 4 - Spearman Correlation (QEQ Versus IIEF, QEQ Versus RAND 36-Item Health Survey, QEQ Versus Aging and QEQ Versus Sexual Intercourse Frequency).

Quality of Erections Questionnaires versus

International Index of Erectile Function SCORE

Total

$r=0.73 p<0.0001$

Erectile Function

$r=0.71 p<0.0001$

Orgasmic Function

$r=0.51 p<0.0001$

Sexual Desire

$r=0.36 p<0.0001$

Intercourse Satisfaction

$r=0.64 p<0.001$

Overall Satisfaction

$r=0.73 p<0.0001$

RAND 36-Item Health Survey Score

Total

$r=0.40 p<0.0001$

Physical Functioning

$r=0.37 p<0.0001$

Role Limitations Due

$r=0.34 p<0.0001$

Physical Problems

Role Limitations Due

$r=0.20 p=0.0042$

Emotional Problems

Vitality

$r=0.23 p=0.0010$

General Mental Health

$r=0.23 p=0.0012$

Social Functioning

$r=0.19 p=0.0059$

Bodily Pain

$r=0.14 p=0.0430$

General Health

$r=0.38 p<0.0001$

Perceptions

Participants Age

QEQ score

$r=-0.32 p<0.0001$

Sexual Intercourse Frequency

QEQ score

$r=0.45 p<0.0001$
Non self-reported ED male infertility out-patients were intentionally included in the study to fill the patient gap in the QEQ development and validation in English. Only 1.25\% of the patients studied by Porst et al. 2007 did not present ED or presented mild ED according to the IIEF classification (13).

The Portuguese version of the QEQ filled in this gap, since we obtained good correlations both in IIEF mild ED patients as well as non-ED patients. Additionally, the Portuguese QEQ version yielded psychometric properties similar to those of the original English version, with high internal consistency and high stability between test and retest.

An ED patient subgroup was absent in the retest. To better understand this fact, we investigated the causes of absence. Our hypotheses included lack of financial means and/or low education level that might have made access to a retest difficult, neither of which was confirmed by statistical analysis. Statistical significance was observed only for self-reported hypercholesterolemia between groups, which was interpreted as a random result without any clinical correlation.

The use of the QEQ Portuguese version is recommended for the evaluation of the response of Brazilian men to ED treatment based on its excellent psychometric properties and its easy and rapid application. On responding the QEQ, the patients do not need to recall each of the aspects involved in sexual intercourse, but rather the quality and satisfaction with their erections in the previous month $(11,13)$.

Table 5 - Correlation between Quality of Erections Questionnaires Score and Erectile Dysfunction (ED) degree.

\begin{tabular}{lccccccc}
\hline Grade & Score & $N$ & Mean QEQ & Median QEQ & Min-Max & SD & $p$ \\
\hline Normal & $26-30$ & 38 & 91.12 & 95.82 & $58.33-100$ & 11.22 & \\
Mild ED & $22-25$ & 22 & 69.12 & 68.75 & $29.16-100$ & 18.92 & \\
Mild-To-Moderate ED & $17-21$ & 23 & 59.42 & 62.50 & $8.33-100$ & 25.35 & $<0.001$ \\
Moderate ED & $11-16$ & 38 & 39.03 & 37.50 & $0-100$ & 24.13 & \\
Severe ED & $1-10$ & 71 & 23.88 & 12.50 & $0-100$ & 28.61 & \\
\hline
\end{tabular}


Table 6 - Correlation between RAND 36-Items Health Survey (RAND) and Erectile Dysfunction (ED) Grade According International Index of Erectile Function (IIEF).

\begin{tabular}{lccccccc}
\hline Grade & Score & N & Mean RAND & Median RAND & Min-Max & SD & P \\
\hline IIEF Normal & $26-30$ & 38 & $85.96 \%$ & $88.27 \%$ & $60.71-98.19 \%$ & 8.66 & $<0.001$ \\
IIEF Mild ED & $22-25$ & 22 & $73.12 \%$ & $76.60 \%$ & $35-94.03 \%$ & 14.51 & $\mathrm{~ns}$ \\
IIEF Mild-to-Moderate ED & $17-21$ & 23 & $62.09 \%$ & $66.67 \%$ & $16.81-93.43 \%$ & 20.58 & $\mathrm{~ns}$ \\
IIEF Moderate ED & $11-16$ & 38 & $62.81 \%$ & $66.67 \%$ & $29.72-90.83 \%$ & 18.21 & $\mathrm{~ns}$ \\
IIEF Severe ED & $1-10$ & 71 & $61.42 \%$ & $62.92 \%$ & $8.75-92.92 \%$ & 22.61 & $\mathrm{~ns}$ \\
\hline
\end{tabular}

ns = non significant

The current version of the QEQ deals with the patients' perspective by including physical, psychological and social wishes $(10,11,14,27$, 28) and sexual satisfaction. Patients with mild ED according to the IIEF classification may be rather dissatisfied while patients with severe ED may not be dissatisfied. The QEQ has the power to discriminate patients dissatisfied with their erection and thus driven to follow the proposed treatment $(13,15)$.

The impact of sexual dysfunction on QoL has been demonstrated by various studies (2934). The expectation of a significant correlation between QoL and ED severity has not been confirmed. A significant difference in QoL was observed only in self-reported ED men, followed by non-ED infertile men. Only the general health perception subdomain of the RAND-36 presented significant difference between mild ED and moderate ED and between mild ED and severe ED patients.

In our sample, this correlation may have been influenced by the global evaluation of the patients. We point out that other factors besides ED may have affected the QoL of the studied population such as urinary incontinence, aches and osteoarticular pains. Additionally, at the time of evaluation, the mean ED length of time before complaint was 4.9 years (min 0.3 and max. 25 years) and the mean age of ED respondents was 57 years old.

The questionnaire scores correlated with the effects on QoL only in ED patients in comparison to non-ED patients, which was expected considering that non-ED patients presented fewer comorbidities such as diabetes, dyslipidemia and hypertension $(p<0.001)$ and lower rates of alcoholism $(p=0.01)$. However, the comparison of the QoL of mild-to-severe ED patients, according to the IIEF, gave similar and non significant values in relation to QoL measured with the RAND-36. We attributed this fact to the time elapsed since the beginning of the symptoms and the moment of evaluation and the patients' "adaptation" to their condition.

Studies have demonstrated the existence of psychological mechanisms that affords a well-being feeling to individuals even in adverse conditions. Generally, after three months, the individuals can interpret negative events such as the permanence of ED in a way that allows them to overcome it and minimize its impact on their QoL. This psychological transformation occurs unconsciously and automatically. Evidence shows that around the age of 60 , negative events are overcome and even reconstructed even faster probably as a result of emotional learning over the years of life (35).

In fact, it has been described that only a small number of ED patients seek treatment spontaneously (36-38). In Brazil, only 21\% of men with some form of sexual dysfunction seek specialized counseling and treatment (39), among which $30-57 \%$ of those who start treatment stop using ED medication (40-42).

The patients' lack of initiative to seek treatment is justified by a lack of perception of the severity of the disease and also because they consider ED a minor problem $(37,39)$. We believe that these justifications agree with the action of 
a psychological mechanism that minimizes the impact of ED on the QoL.

Van Damme-Ostapowicz, 2012 (43) reported a significant correlation between disease acceptance and better QoL indexes measured with specific questionnaires. Gades, 2009 (44) found evidence that despite the greater incidence of ED and greater functional loss with aging, the perception of ED as a problem tends to be minimized and despite the loss of QoL, dissatisfaction is little reported. Datta, 1989 (45) reported similar results in chronic diseases when the time elapsed allowed the patients to adapt to the loss of specific functions.

A study by Lindau et al., 2010 (46) revealed a correlation between better general health scores with sexual satisfaction in men and women and proposed using this correlation to improve treatment adherence and the modification of hazardous habits such as smoking.

While in men the erectile function and sexual satisfaction are affected by cardiovascular diseases, diabetes and prostate cancer, in women sexual satisfaction is situational and depends on the partner. Elderly men are more sexually active than women of similar age. In the 57-64 age group, $76.7 \%$ of the men and only $35.9 \%$ of the women reported interest in sex.

The general QoL questionnaire used in this study, RAND-36, has questions similar to those of the SF-36, which has already been translated to Portuguese and validated in Brazil (47), but has a simpler score developed by the International Resource Center for Health Care. The RAND-36 properties and design have good reproducibility, validity and susceptibility to alterations (16).

\section{CONCLUSIONS}

The Portuguese version of the QEQ presented high internal consistency and excellent stability between test and retest ( $\mathrm{r}=0.82)$, in addition to good psychometric properties. It also presented strong correlations with the IIEF ED severity classification in the erectile function domain, which stimulates its use in further studies of the Brazilian population.

Differences in QoL as measured with the RAND-36 were observed only among patients with normal erectile function and those who complained about ED. Our study did not demonstrate a statistically significant association between ED severity and QoL worsening.

\section{CONFLICT OF INTEREST}

None declared.

\section{REFERENCES}

1. Moreira Jr ED, Abdo CHN, Torres EB, Lobo CFL, Fitipaldi JAS. Prevalência e fatores de risco da disfunção erétil no Brasil: resultados do estudo multicêntrico de comportamento sexual. Rev Bras Med 2001; 58: 515-22.

2. Feldman HA, Goldstein I, Hatzichristou DG, Krane RJ, McKinlay JB. Impotence and its medical and psychosocial correlates: results of the Massachusetts Male Aging Study. J Urol. 1994;151:54-61.

3. Schouten BW, Bosch JL, Bernsen RM, Blanker MH, Thomas $\mathrm{S}$, Bohnen AM. Incidence rates of erectile dysfunction in the Dutch general population. Effects of definition, clinical relevance and duration of follow-up in the Krimpen Study. Int J Impot Res. 2005;17:58-62.

4. Martín-Morales A, Moncada Iribarren I, Cruz Navarro N, Sanz Terrada B, Cassinello Hervás A, Chan M, et al. Efficacy and safety of two dosing regimens with Tadalafil in Spanish men with erectile dysfunction: results from the SURE study in 14 European countries. Actas Urol Esp. 2006;30:791-800.

5. Lindau ST, Schumm LP, Laumann EO, Levinson W, O'Muircheartaigh CA, Waite LJ. A study of sexuality and health among older adults in the United States. N Engl J Med. 2007;357:762-74.

6. Heruti RJ, Steinvil A, Shochat T, Saar N, Mashav N, Arbel $\mathrm{Y}$, et al. Screening for erectile dysfunction and associated cardiovascular risk factors in Israeli men. Isr Med Assoc J. 2008 0ct;10(10):686-90.

7. Serefoglu EC, Atmaca AF, Dogan B, Altinova S, Akbulut $Z$, Balbay MD. Problems in understanding the Turkish translation of the international index of erectile function. $J$ Androl. 2008;29:369-73.

8. Reis $\mathrm{MM}, \mathrm{Abdo} \mathrm{CH}$. Prevalence of erectile dysfunction as defined by the International Index of Erectile Function (IIEF) and self-reported erectile dysfunction in a sample of Brazilian men who consider themselves healthy. J Sex Marital Ther. 2010;36:87-100.

9. Moreira ED Jr, Lbo CF, Diament A, Nicolosi A, Glasser DB. Incidence of erectile dysfunction in men 40 to 69 years old: results from a population-based cohort study in Brazil. Urology. 2003;61:431-6. 
10. Rosen RC, Althof SE, Giuliano F. Research Instruments for the Diagnosis and Treatment of Patients with Erectile Disfunction. Urology 2006; 68 (Suppl 3A): S6-S16.

11. Cappelleri JC, Stecher VJ. An assessment of patient-reported outcomes for men with erectile dysfunction: Pfizer's perspective. Int J Impot Res. 2008;20:343-57.

12. Levinson AW, Ward NT, Sanda MG, Mettee LZ, Wei JT, Su LM, et al. Comparison of validated instruments measuring sexual function in men. Urology. 2010;76:380-6.

13. Porst H, Gilbert C, Collins S, Huang X, Symonds T, Stecher $V$, et al. Development and validation of the quality of erection questionnaire. J Sex Med. 2007;4:372-81.

14. Kaminetsky JC, Depko AJ, Ströberg P, Buvat J, Tseng LJ, Stecher VJ. In men with erectile dysfunction, satisfaction with quality of erections correlates with erection hardness, treatment satisfaction, and emotional well-being. J Sex Med. 2009;6:800-8.

15. Lowy M, Collins S, Bloch M, Gillman M, Lording D, Sutherland $P$, et al. Quality of erection questionnaire correlates: change in erection quality with erectile function, hardness, and psychosocial measures in men treated with sildenafil for erectile dysfunction. J Sex Med. 2007;4:83-92.

16. VanderZee $\mathrm{KI}$, Sanderman R, Heyink JW, de Haes $H$. Psychometric qualities of the RAND 36-Item Health Survey 1.0: a multidimensional measure of general health status. Int J Behav Med. 1996:3:104-22.

17. Ferraz MB, Ciconelli JRM. Tradução e adaptação cultural do índice internacional de função erétil para a língua portuguesa. Rev Bras Med 1998;55:35-40.

18. Gonzáles AI, Sties SW, Wittkopf PG, Mara LS, Ulbrich AZ, Cardoso FL, et al. Validation of the International Index of Erectile Function (IIFE) for use in Brazil. Arq Bras Cardiol. 2013;101:176-82.

19. Rosen RC, Cappelleri JC, Gendrano N 3rd. The International Index of Erectile Function (IIEF): a state-of-the-science review. Int J Impot Res. 2002;14:226-44.

20. Ware JE Jr, Sherbourne CD. The MOS 36-item short-form health survey (SF-36). I. Conceptual framework and item selection. Med Care. 1992;30:473-83.

21. Claes H, Opsomer RJ, Andrianne R, Vanbelle S, Albert A, Vanderdonck F. Characteristics and expectations of patients with erectile dysfunction: results of the SCORED study. Int J Impot Res. 2008;20:418-24.

22. Cappelleri JC, Rosen RC. The Sexual Health Inventory for Men (SHIM): a 5-year review of research and clinical experience. Int J Impot Res. 2005;17:307-19.

23. Lue TF, Broderick GA. Evaluation and nonsurgical management of erectile dysfunction and premature ejaculation. In: Wein AJ, ed. Campbell-Walsh Urology. Saunders: Philadelphia, PA. 2007; pp. 750-87.

24. Costa MR, Reis AM, Pereira BP, Ponciano VC, Oliveira EC. Associated factors and prevalence of erectile dysfunction in hemodialysis patients. Int Braz J Urol. 2014;40:44-55.
25. Araujo AB, Mohr BA, McKinlay JB. Changes in sexual function in middle-aged and older men: Iongitudinal data from the Massachusetts Male Aging Study. J AM Geriatr Soc. 2004;52:1502-9.

26. Instituto Brasileiro de Geografia e Estatística. Senso populacional brasileiro: resultados do ano de 2010. Avaliable at: http://www.cens02010.ibge.gov.br accessed: november 2013.

27. Hedgepeth RC, Labo J, Zhang L, Wood DP Jr. Expanded Prostate Cancer Index Composite versus Incontinence Symptom Index and Sexual Health Inventory for Men to measure functional outcomes after prostatectomy. J Urol. 2009;182:221-7; discussion 227-8.

28. Fisher WA, Rosen RC, Mollen M, Brock G, Karlin G, Pommerville P, Goldstein I, Bangerter K, Bandel TJ, Derogatis LR, Sand M. Improving the sexual quality of life of couples affected by erectile dysfunction: a doubleblind, randomized, placebo-controlled trial of vardenafil. J Sex Med. 2005;2:699-708.

29. Montorsi F, Padma-Nathan H, Glina S. Erectile Function and Assessments of Erection Hardness Correlate Positively with Measures of Emotional Well-being, Sexual Satisfaction, and Treatment Satisfaction in Men with Erectile Dysfunction Treated With Sildenafil Citrate (Viagra®). Urology 2006; 68 (Suppl 3A): S26-S37.

30. Fernandes GV, dos Santos RR, Soares W, de Lima LG, de Macêdo BS, da Fonte JE, de Carvalho BS, Coelho SN, Calado AA. The impact of erectile dysfunction on the quality of life of men undergoing hemodialysis and its association with depression. J Sex Med. 2010;7:400310.

31. Avasthi A, Grover S, Bhansali A, Dash RJ, Gupta N, Sharan $P$, Sharma S. Erectile dysfunction in diabetes mellitus contributes to poor quality of life. Int Rev Psychiatry. 2011;23:93-9.

32. Pereira RF, Daibs YS, Tobias-Machado M, Pompeo AC. Quality of life, behavioral problems, and marital adjustment in the first year after radical prostatectomy. Clin Genitourin Cancer. 2011;9:53-8.

33. Kyrdalen AE, Dahl AA, Hernes E, Småstuen MC, Fosså SD. A national study of adverse effects and global quality of life among candidates for curative treatment for prostate cancer. BJU Int. 2013;111:221-32.

34. Mallis D, Moisidis K, Kirana PS, Papaharitou S, Simos G, Hatzichristou D. Moderate and severe erectile dysfunction equally affects life satisfaction. J Sex Med. 2006;3:442-9.

35. Wilson TD, Gilbert DT. Affective Forecasting. Adv Exp Soc Psychol 2003; 35: 345-411.

36. Moreira ED, Glasser DB, Nicolosi A, Duarte FG, Gingell C; GSSAB Investigators' Group. Sexual problems and helpseeking behaviour in adults in the United Kingdom and continental Europe. BJU Int. 2008;101:1005-11. 
37. Laumann EO, Glasser DB, Neves RC, Moreira ED Jr; GSSAB Investigators' Group. A population-based survey of sexual activity, sexual problems and associated help-seeking behavior patterns in mature adults in the United States of America. Int $\mathrm{J}$ Impot Res. 2009;21:171-8.

38. Buvat J, Glasser D, Neves RC, Duarte FG, Gingell C, Moreira ED Jr; Global Study of Sexual Attitudes and Behaviours (GSSAB) Investigators' Group. Sexual problems and associated help-seeking behavior patterns: results of a population-based survey in France. Int J Urol. 2009;16:632-8.

39. Moreira Junior ED, Glasser D, Santos DB, Gingell C. Prevalence of sexual problems and related help-seeking behaviors among mature adults in Brazil: data from the global study of sexual attitudes and behaviors. Sao Paulo Med J. 2005;123:234-41.

40. Sato Y, Tanda H, Kato S, Onishi S, Nitta T, Koroku M. How long do patients with erectile dysfunction continue to use sildenafil citrate? Dropout rate from treatment course as outcome in real life. Int J Urol. 2007;14:339-42; discussion 343.

41. Carvalheira AA, Pereira NM, Maroco J, Forjaz V. Dropout in the treatment of erectile dysfunction with PDE5: a study on predictors and a qualitative analysis of reasons for discontinuation. J Sex Med. 2012;9:2361-9.

42. Jiann BP, Yu CC, Su CC, Tsai JY. Compliance of sildenafil treatment for erectile dysfunction and factors affecting it. Int J Impot Res. 2006;18:146-9.

43. Van Damme-OstapowiczK, Krajewska-KułakE, Rozwadowska E, Nahorski WL, Olszański R. Quality of life and satisfaction with life of malaria patients in context of acceptance of the disease: quantitative studies. Malar J. 2012;11:171-95.
44. Gades NM, Jacobson DJ, McGree ME, St Sauver JL, Lieber MM, Nehra A, et al. Longitudinal evaluation of sexual function in a male cohort: the Olmsted county study of urinary symptoms and health status among men. J Sex Med. 2009;6:2455-66.

45. [No Authors] Psychology of limb loss. BMJ. 1989;299:1526-7.

46. Lindau ST, Gavrilova N. Sex, health, and years of sexually active life gained due to good health: evidence from two US population based cross sectional surveys of ageing. BMJ. 2010;340:c810.

47. Cicconelli RM, Ferraz MB, Santos W, Meinão I, Quaresma MR. Tradução para a língua portuguesa e validação do questionário genérico de qualidade de vida SF-36 (Brasil SF36). Rev Bras Reumatol 1999; 39: 143-50.

Correspondence address:

Leonardo Oliveira Reis, MD, $\mathrm{PhD}$ Medicine (Urology), Center for Life Sciences, Pontifical Catholic University of Campinas (PUC-Campinas), Brazil Department of Surgery (Urology), Faculty of Medical Sciences, University of Campinas (Unicamp) Rua Tessália Vieira de Camargo 126

Cidade Universitária Zeferino Vaz Campinas, São Paulo, 13083-887, Brazil E-mail: reisleo.l@gmail.com 